University of Nebraska - Lincoln

DigitalCommons@University of Nebraska - Lincoln

Sociology Department, Faculty Publications

Sociology, Department of

2020

The Stress Mechanisms of Adolescent Physical, Mental, and

Behavioral Health

Lisa Kort-Butler

Follow this and additional works at: https://digitalcommons.unl.edu/sociologyfacpub

Part of the Family, Life Course, and Society Commons, and the Social Psychology and Interaction Commons

This Article is brought to you for free and open access by the Sociology, Department of at DigitalCommons@University of Nebraska - Lincoln. It has been accepted for inclusion in Sociology Department, Faculty Publications by an authorized administrator of DigitalCommons@University of Nebraska - Lincoln. 


\title{
The Stress Mechanisms of Adolescent Physical, Mental, and Behavioral Health
}

\author{
Lisa A. Kort-Butler \\ University of Nebraska-Lincoln
}

\begin{abstract}
Although the mechanisms are complex, stress is a risk factor for compromised physical, mental, and behavioral health in adolescence. The stress paradigm posits a system of relationships among social structures, stressors, personal and social resources, and health outcomes, offering a framework for understanding how adolescents' life problems and the means to cope with them affect well-being. This chapter reviews the theoretical underpinnings of the stress paradigm, drawing on the stress process model and general strain theory. The chapter briefly reviews the biological underpinnings of stress and the role of brain development. Then, the chapter focuses on the social aspects of the adolescent stress experience, including the nature of stressors, key domains of adolescent stress, and the process of stress proliferation. Next, the chapter details the mechanisms linking stressors to health outcomes, including the stress appraisal process and the role of personal and social resources (e.g., coping styles; self-esteem and mastery; social support) in shaping adolescents' responses to stressful experiences. The chapter concludes with the implications of the stress paradigm for future research and policy in adolescent health and delinquency.
\end{abstract}

The experience of stress has implications for physical, mental, and behavioral health among adolescents. Research points to shared antecedents and common etiologies of these problems, as well as models that suggest one set of problems may precipitate the others (Hagan

Pre-print. Kort-Butler, Lisa A. 2020. “The Stress Mechanisms of Adolescent Physical, Mental, and Behavioral Health.” Pp. 74-89 in Routledge International Handbook of Delinquency and Health, Michael G. Vaughn, Christopher P. Salas-Wright, and Dylan B. Jackson (eds.). New York: Routledge. Copyright (C) 2020 Taylor \& Francis. Used by permission. 
\& Foster, 2003; Lee \& Stone, 2012; Wade \& Pevalin, 2005). Adolescence is often viewed as a period of storm-and-stress, but those experiences are a product of the cultural and social conditions in which adolescents live (Arnett, 1999). The stress paradigm posits a system of relationships among social structures, stressors, social and personal resources, and health outcomes (Aneshensel \& Mitchell, 2014). The roots of and risks related to adolescents' physical, mental, and behavioral health needs are complex, but the stress paradigm offers a framework for understanding how life problems and the means to cope with them affect adolescents' ability to resist illnesses and to self-regulate behaviors.

This chapter reviews the theoretical underpinnings of the stress paradigm, drawing primarily on the stress process model, developed to understand the stress-health/mental health link (Pearlin, 1989), and general strain theory, developed to understand the stress-criminality link (Agnew, 1992). To begin, I highlight the biological forces and social realities surrounding the adolescent stress experience. Then, I describe the stress paradigm model dovetailing the stress process model and general strain theory. This is followed with a discussion of the nature of stressors and key domains of stress during adolescence, as well as the mechanisms by which stress impacts adolescents' health and well-being. Finally, I conclude the chapter with the implications of the stress paradigm for future research and policy.

\section{Biological Forces, Social Realities}

Stress, at its most basic, is a physiological response. Stressors - also referred to as strains - are challenging events, demanding situations, or roadblocks to or absence of the means to pursue goals, which ignite a stress response (Aneshensel \& Mitchell, 2014). Stressors activate processes along the hypothalamic-pituitary-adrenocortical (HPA) axis, designed to maintain increased energy and vigilance to deal with the threat posed by stressors (Lucas-Thompson et al., 2017). This promotes short-term adaptation - allostasis. If the situation is remedied or the person can cope, then readiness subsides. If not, however, then the physiological reaction may not subside, contributing to a dysregulation of allostasis. As stressors persist or accumulate, the person lives 
with an elevated allostatic load. This state compromises the body's neuroendocrine, immune, metabolic, and cardiovascular functioning, as well as stress resiliency, ultimately contributing to a range of negative health outcomes (Juster, McEwen, \& Lupien, 2010; McEwen \& Gianaros, 2010).

Research confirms that the adolescent brain is still developing, with the limbic structures that drive the seeking of rewards, risks, and novel experiences outpacing the prefrontal control structures that regulate decision-making, emotional reactivity, and effective coping (Casey, Jones, \& Somerville, 2011). Adolescents are capable of making rational decisions and understanding the risks associated with choices, but under stressful or emotionally-charged situations the more developed limbic system takes control. These features of brain development shape how adolescents appraise and respond to stressors (McEwen \& Gianaros, 2010). Moreover, stressful experiences influence the structure of the developing adolescent brain, adding to the complex mechanisms linking stress and well-being (Romeo, 2017).

Yet adolescents are more than the sum of their biological responses. The experience of stress is deeply personal while embedded in social context, a consequence of social organization and an individual's location within it (Sigfusdottir, Kristjansson, Thorlindsson, \& Allegrante, 2016). Importantly, stressful experiences are one way social structure is linked to well-being (Pearlin, 1999). Social conditions, structures of inequality, and socialization experiences shape the nature of stressors people confront, their assessment of those stressors, the resources they have available to cope with stressors, and their ability to deploy those resources in a way that successfully manages stress. Moreover, one's stage in the life course has particular importance in shaping the stressors one encounters and the range and effectiveness of coping responses.

Adolescence, while a period of biological and cognitive development, is also socially defined (Gore and Colten 1991). It is a period in which young people begin to try out adult statuses, rehearse culturally-appropriate role definitions, and solidify identities (Hagan \& Foster, 2003). There are stressors unique to adolescence: adult expectations and family relationships, school pressures, peer relationships (e.g., dating, bullying), and higher risk for victimization. Differences in cognitive, emotional, and social development affect what 
adolescents see as stressful, the resources they can draw together to manage stress, and how they respond to perceived problems (SeiffgeKrenke, Aunola, \& Nurmi, 2009). Learning to cope with stress effectively is among all the other developmental goals of adolescence.

\section{The Stress Paradigm}

Both the stress process model (Pearlin, 1989, 1999) and general strain theory (Agnew, 1992, 2006) predict that the occurrence of stressful experiences can activate sequences that result in problems like poor health, poor mental health, and delinquency. The stress process model suggests that stressful experiences tax the individual's ability to adapt, putting pressure on the body or mind. The lack of personal and social resources detracts from healthy adaptation, and the inability to adapt threatens well-being. The connection between stress and adolescent physical and mental health has generally been supported (Compas, Jaser, Dunn, \& Rodriguez, 2012; Low et al., 2012; Wickrama, Lee, \& Walker, 2015).

General strain theory explicates how negative emotional arousal generated by stressful experiences may be externalized into aggressive actions, substance use, or illict behavior. Negative emotions fear, depression, frustration, anger - create pressure for corrective action. People may use legal or illegal means to address these strains and alleviate the feelings they engender. Anger in particular is implicated in crime, while depression is implicated in substance use (Jang \& Johnson, 2003). The likelihood that people turn to illegitimate actions is based on social psychological protective factors and criminal propensity. The connection between strain and delinquent outcomes has generally been supported (Moon, Morash, McClusky, \& Hwang, 2009; Sigfusdottir, Kristjansson, \& Agnew, 2012).

Both perspectives hinge on a variety of mechanisms connecting stressors and health-related outcomes, detailed below. I offer a unified description of the core process here (Agnew, 2006; Aneshensel \& Mitchell, 2014; Wheaton, 2010). Social conditions and structured inequalities shape the context in which the process unfolds, holding both distal and direct effects. When stressors occur, they are appraised. Subjective appraisal forms the basis of the individual's physiological and emotional arousal. Stressors can also have direct effects 
on physiological arousal and well-being, particularly in moments when appraisal or other elements of the process are overwhelmed (e.g., extreme or sudden trauma).

Personal and social resources, including coping style, self-esteem and mastery, and social support, influence stress appraisal and adaptation to stressors. Physiological and psychological responses to stressors, as well as behavioral responses (e.g., lashing out, self-medicating) may ultimately lead to disease, mental illness, and delinquency. Personal and social resources serve mediating functions, in which stressors activate or suppress coping responses, or even deplete resources, impacting well-being. They also act as moderating or buffering constructs, which may prevent, hinder, or advance healthy adaptations to stress. People with higher levels of these resources have a wider repertoire with which they can manage stress and are therefore more protected from its damaging effects.

Stressors act in an indeterminate manner, such that their impact is not limited to a single disease or disorder but may be manifested across a spectrum of physical and mental health outcomes (Aneshensel \& Mitchell, 2014). General strain theory points to a variety of behavioral outcomes that can also be impacted by stressors: aggressive acts, instrumental acts (e.g., theft), and escapist acts (e.g., drug use, running away) (DeCoster \& Kort-Butler, 2006). The harmful effects of exposure to stressors and vulnerability to stressful experiences are not inherent to a particular stressor or category of stressors; rather, problems result from an interaction with attributes and resources of the individual and their social circumstances. It is this continuum of outcomes that make the stress paradigm useful for understanding adolescent health and delinquency. To detect possible differences in the ways in which social groups manifest problems with well-being, and to observe the range and specificity of outcomes that strain might generate, it is necessary to bring together information about different outcomes.

\section{Social Stressors}

The universe of stressors can be placed along continuums of duration (discrete to chronic), severity, life course stage, and level of social context. Identifying separate types of stressors allows us to distinguish 
between the problems of identity threat and identity adjustment (e.g., life events) and the problems of continual vigilance and pressure (e.g., chronic stressors) (Wheaton et al., 2013, p. 304). Considering the level of context frames the range of stress exposure in a population, recognizing the several environments in which people are immediately embedded - families, schools, community groups - which themselves are bounded by neighborhoods or cities. Events happening at these mid-range levels may also be experienced as stressful, just as larger scale social stressors may have cascading effects on midrange situations and even interpersonal relationships. Taking context into account also clarifies the distinction not only among personally experienced stressors, but also witnessed, vicarious, and anticipated stressors (Agnew, 2002). The universe of stressors cannot be fully understood apart from social context, illustrating how stressful experiences overlap, intertwine, and proliferate in the lives of young people (Sigfusdottir et al., 2016).

\section{Key Stress Domains for Adolescents}

For adolescents, family, school, and peer groups are key stress domains (DeCoster \& Kort-Butler, 2006; Wade, Shea, Rubin, \& Wood, 2014). Families may be the source of arguments and conflicts with parents or siblings, as well as a range of adverse experiences, such as economic hardship, abuse and neglect, domestic violence, divorce, parental incarceration, parental mental illness or substance use (Balistreri \& Alvira, 2016). Because school and school-related activities figure prominently in the lives of adolescents, problems at school, such as conflict with teachers, struggles with academic work, troubles with or exclusion from extracurricular activities, as well as a deleterious school environment, are unique sources of adolescent strain. Peer relationships, which adolescents are learning to navigate on their own, may be particularly meaningful, including peer pressures, arguments with friends, break-ups, social exclusion and rejection, dating violence, and bullying.

Normative changes and developmental tasks weave through these domains: concerns about body, identity, and fitting in; gaining independence; establishing and navigating romances; expectations and concerns about future educational and occupations goals (Knight et 
al., 2017; Seiffge-Krenke et al., 2009). Experiences of trauma and victimization, both experienced and witnessed, may be located within a specific domain but have cross-cutting and potentially long-lasting effects (Bouffard \& Koeppel, 2014). Experiences of discrimination and stigma also have cross-cutting effects, especially as adolescents begin to confront these experiences on their own (DeCoster \& Thompson, 2017). Neighborhoods themselves may be sources of strain (e.g., environmental hazards; social disadvantages) and frame the likelihood of encountering trauma and discrimination (Warner \& Setterson, 2016). They also create de facto boundaries for families, schools, and peer relationships, shaping the strains experienced in those domains and the resources available to cope with strain.

\section{Stress Proliferation}

Identifying different categories of stressors is helpful when thinking about the range of troubles adolescents might face, and how together they contribute to cumulative stress burden or accumulated strain (Thoits, 2010). Such distinctions are empirically and theoretically useful, but people's lived experiences are rarely so neatly categorized (Carr \& Umberson, 2013). The concept of stress proliferation - the idea that stressors beget other stressors - recognizes that a stressful condition may disrupt or alter people's established roles and routines, and may also lead to stressors beyond the life domain in which it occurred (Pearlin, Schieman, Fazio, \& Meersman,, 2005). An acute problem - a sudden trauma, a negative life event - can have cascading consequences that become chronic in nature.

Proliferation may arise along two pathways. One, new stressors within a life domain may arise from an expansion of primary stressors (Pearlin et al., 2005). For example, parental separation may lead to an adolescent taking on new and stressful family responsibilities, such as caring for siblings and more household chores. Two, primary stressors in one domain may spillover, creating secondary stressors in another domain (DeCoster \& Kort-Butler, 2006). For example, parental conflict may affect an adolescent's school performance.

Along both pathways, coping efforts must be directed at the original problem, trying to contain any spillover, and then dealing with the new stressors. These secondary stressors may become the more 
proximate causes of negative outcomes. As stressors accumulate and proliferate, or even become routine, newly arising conditions or events that are objectively minor may have greater potential to undermine health or promote risky behaviors (Botchkovar \& Broidy, 2010). For example, Ferro \& Boyle (2015) found in families of children with chronic illness, that stressor increased maternal and family stress, depleting the child's self-esteem, and increasing their risk for anxiety and depression. The proliferation process also clarifies how adverse early life circumstances are connected to stressors in adolescence and beyond, tying these early experiences to later well-being (Slocum, 2010).

\section{Stress Appraisal}

Objective and subjective experiences of strain only partially overlap (Agnew, 2013). Objective stressors "set the stage" for the sorts of experiences that may be subjectively appraised as stressful. Experiences may be appraised as challenges when a person feels they have enough resources to cope with demands, or as threats when demands exceed resources (Yeager et al., 2016). Both activate physiological responses, although threat appraisals yield more prolonged reactions and allostasic dysregulation, potentially damaging long-term health and cognitive processes. Likewise, subjective perceptions of strain may prime delinquent outcomes (Froggio \& Agnew, 2007). Strains perceived as unjust or of high magnitude or severity provoke emotional responses like anger. Strains of this nature may seem, from a subjective point of view, to overwhelm legitimate coping resources, reduce the perceived costs of illegitimate coping, and promote criminal or risky behaviors.

An adolescent's evaluation of their own skill set, capacities, and access to meaningful resources are fundamental to assessing an event (Seiffge-Krenke et al., 2009). A range of factors may influence the subjective evaluation of objective stressful experiences: individual factors (e.g., personality traits, personal goals and values, role-associated identities, self-esteem); social factors (e.g., social support; peer networks); life circumstances and environmental factors (e.g., family poverty, access to care); and prior attempts at coping with stressful experiences (Froggio \& Agnew, 2007). McLeod (2012) emphasizes that people's interpretations of objective life experiences depend on 
their social location and broader, cultural ideologies. Meaning is negotiated in social context: families, friends, informal and formal groups, schools, communities. People's interpretation of stressors are likely evaluated by others, who help shape the appraisal process. Even in absence of direct interaction, people may compare their own evaluations against the imagined evaluations of others. The social context in which a stressful experience occurs and the appraisal of a stressful situation affect later responses.

\section{Mechanisms of the Stress Paradigm: Key Personal and Social Resources}

Both the stress process model and general strain theory highlight the importance of social psychological and interpersonal resources in shaping the process by which stress affects well-being. These resources include (but are not limited to) coping styles; self-esteem, mastery, and self-efficacy; and social support. Rsources, like stressors, are tied to social structure and context, as well as socialization experiences. Thus, individuals vary in the extent to which they bring resources to bear on stressful situations. Because coping also varies developmentally, resources adolescents use to manage stress and their effectiveness may vary, with consequences for well-being.

Resources, although conceptually distinct, tend to be correlated. For example, adolescents with positive self-esteem are also likely to have higher levels of mastery and social support, just as social support buoys a strong sense of self (Cornwell, 2013; Kort-Butler, 2010). Consequently, people with higher combined levels of resources may be more resilient to the negative effects of stress. More is not always better, as not all resources have the same capacity to protect against strain (Sealock \& Manasse, 2012). Resources may be more effective in they match-up to the strain domain, e.g., social support from teachers may be especially beneficial for school-related stressors (DeCoster \& Kort-Butler, 2006). Effective coping may also require drawing on a combination of resources from different domains (Foster \& BrooksGunn, 2009).

The mechanisms by which resources steer the stress process are multifaceted. They may influence how an individual appraises a stressor in the first place, how an individual experiences and responds 
to the stressor, and ultimately if/how the stressor undermines health and well-being. Stress researchers refer to processes of mediation and moderation (Aneshensel \& Mitchell, 2014). The key is the availability of these resources to the individual to assist in interpreting and managing the experience of stress (i.e., appraisal and mediation, respectively), and/or their ability to buffer the deleterious effects of stressors on well-being (i.e., moderation). Over time, particularly in conditions of chronic stress, resources may become substantially weakened, as people repeatedly draw on them.

As mediators, resources provide an indirect link between stressful experiences and health outcomes. Resources may be involved in suppressing relationships, in which stressors lead people to "activate" resources, limiting the overall effect of stress on well-being (Wheaton et al., 2013). Resources may also operate in intervening relationships in which stressors deplete resources, resulting in a net negative effect on well-being. Mediating resources are tied to both the stressors that stimulate them and to health outcomes, explaining how stressors operate to undermine health. As moderators, resources may act as buffers between a stressful experience and deleterious outcomes, typically modeled as an interaction term. Those with low levels of resources are left more vulnerable to stress, whereas those with high levels of resources are shielded from the potentially damaging effects. Compared to mediators in the stress process model, moderators do not directly link stress and health per se; instead, they influence the impact of the stressor on the outcome (Pearlin \& Bierman, 2013).

\section{Coping Styles and Strategies}

Coping can broadly be defined as the efforts that people take on their own behalf in an attempt to avoid or lessen the impact of stress and its consequences (Pearlin, 1999). Coping styles are habitual preferences for dealing with problems, which are employed across different stressful situations (Thoits 1995). Although adults may have habitual coping preferences, it is important to remember adolescents are still developing these preferences. There are several ways to categorize coping styles among adolescents; they share three broad themes (Compas et al., 2012; Seiffge-Krenke, 2000). An active or approach-oriented coping style entails actions to alter the stressor or being proactive 
in managing one's emotional reaction to stressor (e.g., seeking support, discussing the problem, acquiring information and material resources). An internal or cognitive coping style entails efforts to adapt to the stressor with cognitive reappraisal, or thinking over the problem and considering courses of action. An avoidant coping style entails attempts to physically or cognitively "get away" from a stressor or one's emotional response to it (e.g., withdrawal, distraction, denial).

Coping styles may influence stress appraisal and also act a moderating mechanisms that cushion (or amplify) the effect of the stressors on outcomes. Coping strategies, drawn from an individual's coping style, are behavioral and/or cognitive tactics to manage specific situational demands that are appraised as stressful (Carr \& Umberson, 2013; Seiffge-Krenke et al., 2009). As mediators in the stress process, coping strategies may function to: change the situation from which stressors arise; manage the meaning of the situation in a way that reduces its threat; keep the symptoms of stress manageable; or inhibit the emergence of secondary stressors (Pearlin, 1999). Across adolescence there is typically an increase in the use of problem-solving strategies and a decline in avoidance strategies (Amirikhan \& Auyeung, 2007). As adolescents try out different strategies, they may apply them inconsistently or inefficaciously (Zimmer-Gembeck \& Skinner, 2011).

The relationship between coping styles and outcomes of the stress process is complex (Kort-Butler, 2009; Seiffge-Krenke \& Klessinger, 2000). An avoidant style may be beneficial in the short term, but inhibits problem-focused strategies, undermines a sense of control, thereby failing to buffer or even amplifying the impact of stress on physical and mental health. An active coping style facilitates problemsolving and a sense of control, buffering the negative effects of stress and promoting health. When it comes to behavioral health, however, an avoidant style may inhibit someone from acting out aggressively against the source of the stress; an attempt to ignore a situation may also promote a retreat to substance use. An active style may promote problem-solving, but conduct problems could ensue if such strategies are not tempered by restraint. Thus, active coping is generally most beneficial to well-being, but there may be conditions under which it is not and conditions under which avoidant coping is protective.

Matching strategy to stressor is also relevant. Active coping is associated with healthy functioning in the context of controllable stressors 
(i.e., the degree to which objective conditions of a stressor can be eliminated by resources or actions), but negatively associated with health when activated to manage uncontrollable stressors (Clarke, 2006). Internal/cognitive coping, in these circumstances, may be protective (Carr \& Umberson, 2013). Under conditions of chronic stress, however, even effective situational strategies may dwindle over time, becoming less helpful. Maladaptive coping styles may arise as a way of "getting by" or surviving, but they may have long-term negative consequences for well-being.

\section{Self-Esteem, Mastery, and Self-Efficacy}

Self-esteem is an evaluation that a person makes of themselves, expressing approval or disapproval regarding self-worth, rooted in selfcomparison to others and reflected appraisals (Rosenberg, 1989). Low self-esteem among adolescents is tied to poorer mental health outcomes and delinquency (Keane \& Loades, 2016; Mier \& Ladny, 2018). Self-esteem is dynamic during adolescence, declining in early adolescence but rebounding in mid- to late-adolescence (Baldwin \& Hoffman, 2002). Instability is linked to developmental experiences, including biological changes and shifts in roles, responsibilities, and personal identity. Self-esteem is also responsive to relationships with family and friends, life events, and school climate (Greene \& Way, 2005).

A positive and resilient self-image is a crucial resource for combating the sometimes negative implications for the self that accompany personal changes and stressful experiences, as well as for buffering the emotional consequences of stress (Thoits, 1995). Self-esteem helps individuals resist the effects of stress, perhaps by making them less sensitive to its negative qualities, facilitating productive and legitimate coping efforts, and promoting healthy outcomes (Trzesniewski et al., 2006). Self-esteem may mediate the effect of childhood and family stressors on emotional and behavior problems and substance use in adolescence (Arslan, 2016; Voisin, Kim, Bassett, \& Marotta, 2018).

Mastery is an individual's sense of their ability to control the forces that affect their life (Mirowsky \& Ross, 2003). Self-efficacy, a similar construct, refers to the belief in one's capability to exercise control over events, to confront and handle problems, and to perform effectively by one's own efforts (Burger \& Samuel, 2017). With this sense 
of personal control, a person may be more attentive to problems, and more active and successful in solving them. Like self-esteem, self-efficacy is dynamic during adolescence, fluctuating during times of transition, and is responsive to inputs from the social environment (Burger \& Samuel, 2017).

A sense of mastery may directly reduce psychological distress and buffer the harmful effects of stress exposure on health (Mirowsky \& Ross, 2003; Turner, 2010). People who have a high level of mastery may see stressors as less threatening and ominous and have a greater sense of self-confidence, which counteracts discouragement in the face of stress (Mirowsky \& Ross, 2003). Although studies have tended to focus on life events or trauma, self-efficacy also has protective functions from adolescents' daily stress hassles and from the effects of neighborhood context (Dupéré, Leventhal, \& Vitaro, 2012; Schönfeld, Brailovskaia, Bieda, Zhang, \& Margraf, 2015).

Mastery and self-efficacy facilitate legitimate coping efforts in the face of strain, as people with high levels of mastery are more likely to see their strain as manageable through nondelinquent means (Hoffman and Cerbone 1999). A sense of mastery may also make it less likely for individuals to externalize blame for stressful events, so they may seek personal solutions rather than acting out. However, Agnew (2006) also described a kind of criminal self-efficacy, the extent to which people feel they can solve problems illegitimately. Among some adolescents, particularly those exposed to chronic strains or precarious circumstances, self-efficacy may operate to facilitate delinquent outcomes (Tyler, Kort-Butler, Swendener, 2014).

\section{Social Support}

Just as family, teachers, and peers can be a source of stressors, they can also be important sources of support for adolescents (Yeung \& Leadbeater, 2010). Social support is commonly conceptualized as the social resources on which one can rely in dealing with life problems and stressors, typically grounded in personal relationships but also tied to community-level resources (Cullen, Wright, \& Chamlin, 1999; Turner and Lloyd, 1999). Thoits (2011) theorizes that social support can be classified into active coping assistance and emotional sustenance. Active coping assistance involves another person taking 
instrumental action to address a stressor directly, providing information, giving advice, or offering encouragement or distractions. Emotional sustenance involves offering care, concern, or sympathy, validating feelings, or simply "being there" for a person.

Social support may thus provide adolescents a safe haven from negative experiences, offer a way to avoid or navigate stressors, foster resiliency, and facilitate legitimate coping responses in the face of stress (Capowich, Mazerolle, and Piquero, 2001). Social support creates a context in which strong prosocial bonds form and in which parental and other social controls are most efficacious (Cullen, 1994). Parental support is an important source of stress buffering in adolescence, often operationalized as a subjective emotional bond that makes an adolescent feel supported and loved (Meadows, Brown, \& Elder, 2006). As adolescents mature into adulthood and begin to establish their own independent lives, support from others becomes more relevant. Social support - relevant sources, their meaning to the adolescent, and their effectiveness in buffering stress - ebb and flow during adolescence (Cornwell, 2003; Rueger, Malecki, Pyun, \& Aycock, 2016). Evidence consistently demonstrates social support has both direct and buffering effects on well-being (Turner, 2010), including physical, mental, and behavioral health among adolescents (Chu, Saucier, \& Hafner, 2010; Wight, Botticello, \& Aneshensel, 2006).

Adolescents with consistent conventional social support are in a better position to handle stressors, although social context may shape how consequential that support is (Colvin, Cullen, \& Vander Ven, 2002; Wight et al., 2006). Additionally, it is important to recognize that social support involves a degree of social influence via role modeling and encouragement. Thoits (2011) focuses on the positive aspects of this support, but Colvin et al. (2002) contend the lack of positive support may lead people to seek out more illegitimate support sources. For example, Baron (2015) found adolescents who did not feel supported by parents were more likely to have peers supportive of illicit behavior. Support from such sources may influence stress responses along more problematic lines (Brezina \& Azimi, 2018). Like other mechanisms in the stress process, the role of social support is nuanced, once source, type, consistency, and conventionality are considered. 


\section{Additional Mechanisms}

There are several concepts pertinent to adolescence for which there is some preliminary evidence of health-related effects. Mattering - the belief that others are dependent on us and we are important to others - is related to but conceptually distinct from self-esteem and social support, perhaps signaling a sense of social integration that protects from stressors (Lewis, 2017; Turner, 2010). A sense of optimism may be implicated in both stress appraisal and approach-oriented coping, buffering the impact of stressors on health and problem behavior (Knight et al., 2017). Finally, belief systems and values, including religiosity, frame meaning and stress appraisal, and may be tied to unique coping strategies and systems of support (Krok, 2015; Pearlin \& Bierman, 2013).

In addition, general strain theory describes several other factors that connect strain and delinquency, focused around criminal propensity, such as the personality traits of negative emotionality and low constraint, beliefs that crime is justifiable or desirable, reduced social control (i.e., connections to others and conventional activities), and association with criminal others (Agnew, 2006). Delinquency and other risky behaviors are situational responses, so moderators are particularly relevant; people high in criminal propensity are more likely to make riskier decisions in a given situation. However, the inconsistent moderating effects of individual factors have led to research using composite moderators of propensity (Baron, 2018), with the idea that the overall standing on these factors may together affect the likelihood of responding to strain with crime (Agnew, 2013). This research is in its early stages, but the evidence also appears mixed (e.g., Craig, Cardwell, \& Piquero, 2017; Moon \& Morash, 2017). In part, the inconsistent moderating effects for criminal propensity may be due to the challenges of measuring situational responses in surveys, and the wide variation in how those concepts are operationalized.

\section{A Note on Status Differences}

Adolescents' life experiences are shaped by status characteristics such as race-ethnicity (Brown, Meadows, \& Elder, 2007), social class (Wade et al., 2014), gender (Sharp, Brewster, \& Love, 2005), and 
sexuality (Saewyc, 2011), which themselves intersect (Dowd, Palermo, Chyu, Adam, \& McDade, 2011; Goodman et al., 2005). Structured inequalities generate differences in the level and length of exposure to stressors, and produce stressors unique to social positions. Because structured inequalities are also linked to differences in resources, including those that buffer stress, adolescents in disadvantaged social positions may be more vulnerable to the effects of stress. Vulnerability does not necessarily mean resources operate differently. Rather, resources may less available, less impactful, or more easily depleted over time, weakening the ability to cope effectively with new or additional stressors. (Adkins et al., 2009).

\section{Further Considerations}

Although the mechanisms are complex, stress is a risk factor for compromised physical, mental, and behavioral health in adolescence. These effects can be contemporaneous: the stressor is appraised, controllable, the adolescent has resources available, and successfully copes, with no deleterious effect on well-being. The adolescent may make mistakes in appraisal or in bringing the right resources to bear on a problem, resulting in a relatively temporary health problem or a deviant behavioral reaction until the situation can be resolved more effectively. In addition to contemporaneous effects, stressful experiences also create differential risk for precocious entry into and exit from social roles, which may contribute to maladjustment and health problems in young adulthood and beyond (Hagan and Foster, 2003). Research suggests that resources themselves likely shape which stressors people are either protected from or the extent to which they experience them. For some adolescents, stress proliferates, and poor health and harm accumulate as a result.

\section{Poor Health as a Stressor}

The interrelationship among the co-occurring problems of youth remain undertheorized and understudied (Lee \& Stone, 2012; McLeod et al., 2012). Adolescents who engage in delinquency tend to be less healthy than non-delinquents, and stress may partly account for this 
association (Junger, Stroebe, \& Van der Laan, 2001). A criminal lifestyle during one's youth may lead to poor health later in life (Piquero, Daigle, Gibson, Piquero, \& Tibbets, 2007), but among young people, health problems may themselves be a risk factor for mental health problems and delinquency. Chronic health conditions are associated with internalizing and externalizing disorders, as well as substance use and other health risk behaviors (Pinquart \& Shen, 2011; Suris, Michaud, Akre, \& Sawyer, 2008).

Following Agnew's (2006) conceptualization, poor health is a noxious stimuli that may interfere with the achievement of positively valued goals while removing positively valued stimuli from the ill person. Further, individuals may feel their illness is unfair and, depending on the nature of the illness, highly aversive. Poor physical health, as well as related strains such as not being able to access needed care or missing normative activities, may be experienced as stressful and are associated with repercussions that promote psychological distress, delinquency, and substance use (Ford, 2014; Stogner \& Gibson, 2010).

Stress proliferation offers one explanation (Kort-Butler, 2017). For adolescents, health-related strains may lead to stressors in other life domains, such as difficulties with school work, problems with teachers, and missing out on school and social activities, which become more proximate causes for illicit behaviors. If such behaviors persist, they may increase exposure to yet more stressors, which in turn may exacerbate health issues and problem behaviors (Slocum, 2010). Additionally, negative reactions from others to such behaviors may be sources of stress and stigma (McLeod et al., 2012), and signal a withdrawal of social supports that would otherwise have a protective function.

\section{Directions for Research}

Research has identified a range of stressors that impact well-being, but the pursuit of understanding specific stressors is double-edged (Wheaton, 2010). On the one hand, by focusing on one type or domain of stressor, we may overlook how the burden associated with the accumulation of stressors undermines health. On the other hand, by relying only on general or count measures, we fail to detect how stressful experiences interact, spillover, and proliferate in the lives 
of young people. Additionally, the relative effects of objective versus subjective strains remains unsettled (Moon \& Morash, 2017). While subjective measures encapsulate the appraisal process, objective measures may capture the broader context of adolescents' lives. There is more to learn about how to quantify stressors and stress appraisal, how stress ebbs, flows, and/or accumulates in young people's lives, and whether the long-term effects can be averted or reversed (Sigfusdottir et al., 2016).

A particular challenge in studying stress mechanisms is that they can function statistically as both mediators and moderators (Aneshensel \& Mitchell, 2014). Evidence demonstrates these factors are central to health and well-being under stressful circumstances, but understanding how, under what circumstances, for whom, and why mechanisms work remains a theoretical and empirical challenge. The appraisal of the stressor, the physical and emotional reaction to the stressor, the circumstances and context of the stressor, and the person's standing on a host of resources influence mediating and/or moderating effects of a particular mechanism. Research should consider the effects of these mechanisms within and across life domains (DeCoster \& Kort-Butler, 2006; Foster \& Brooks-Gunn, 2009). Proliferation may be contained if resources can be "matched" to life domains, just as coping resources may spillover to support coping in another domain. In addition, we need to explore beyond the individual and consider their social context, what Foster and Brooks-Gunn (2009) describe as multilevel mediators and moderators.

Increasingly sophisticated statistical capabilities have improved our ability to situate individuals in their social environments, as well as our ability to model mediating and moderating effects - alone and in combination. However, we remain restricted in our ability to "see" the process unfold; we need both quantitative and qualitative approaches (McLeod, 2012). Qualitative work can offer insight into how young people appraise stress and mobilize resources, and can be nuanced enough to attune to developmental periods. Interview- and focus group-based studies can explore stress perceptions (Spencer, Walsh, Liang, Mousseau, \& Lund, 2018), the meaning of stress (Rose, Sharpe, Shdaimah, \& deTablan, 2017), the intricacies of intervening mechanisms (Panuccio, Christian, Martinez, \& Sullivan, 2012), and barriers to health care access (Ott, Rosenberger, McBride, \& Woodcox, 2011). 
Mixed methods that collect real-time data offer one approach that may be particularly useful for adolescent populations. For example, ecological momentary assessment using text messaging allows researchers to contact respondents with short survey questions throughout the day about stressful events and health risk behaviors (Tyler, Olson, \& Ray, 2018). Creative methodological approaches are needed to address remaining gaps in knowledge about the mechanisms through which stressors work to increase the likelihood of poor physical and mental health and harmful behaviors in adolescence.

\section{Conclusion}

Adolescent well-being is dynamic, unfolding over time as young people try to negotiate the social world, a world in which they encounter stress and a world significantly structured by their social location and stage in the life course. Biosocial factors, brains mechanisms, and genetic interactions are important auxiliaries to the social psychological model of stress discussed in this chapter (Stogner, 2015). Structural, contextual, and developmental factors, and mechanisms such as stress appraisal, coping, self-esteem and mastery, and social support affect whether and how stress ultimately impacts health. Stress acts in an indeterminate manner, such that its impact is not limited to a single health outcome but may be manifested across a spectrum of physical, mental, and behavioral health. Policies designed to target exposure to stressors and promote equity in health care may help eliminate disparities in adolescent health and generally advance adolescent wellbeing (Thoits, 2010; Turner, 2010; Jackson \& Vaughn, 2018).

We need more research, particularly cross-disciplinary research, to integrate fully across the stress process model and general strain theory. The stress paradigm has a tradition of openness and flexibility, in which new ideas and new evidence are used to specify, and to alter if necessary, the basic concepts and linkages among concepts (Wheaton, 2010, p. 250). Such theoretical and empirical advancements will help us to: better understand the unfolding of stress through childhood to young adulthood; identify the set of circumstances leading to one outcome versus another; and reveal the intertwining of physical, mental, and behavioral health issues (Grant, McMahon, Duffy, Taylor, 
\& Compas, 2010). To craft effective interventions, it is crucial to understand intervening mechanisms and the relative impact of those mechanisms on health outcomes (Thoits, 2011, p. 156).

To that end, health and delinquency research typically emphasizes individual deficits and risky contexts. Yet, prevention and intervention strategies that focus on positive goals (e.g., enhancing strengths, building skills) are preferable to those focused on deficits (Hall et al., 2012, p. 54). Despite the complexities of the stress process, two recommendations emerge from the literature. The first is bolstering conventional social support (Agnew, 2006; Chu et al., 2010; Cullen et al., 1999). Social support fosters resiliency and legitimate coping in the face of strain, promoting healthy, prosocial adaptations. At the individual level, such efforts may focus on fostering supportive relationships with family members, teachers, and other adults in the community (DuBois et al., 2002; Johnson et al., 2011). Schools and communities can also be designed to foster supportive relationships through extracurricular or community groups (Eisman, Lee, Hsieh, Stoddard, \& Zimmerman, 2018; National Research Council, 2002).

The second recommendation is improving access to and providing comprehensive health care, both in the public (Spencer, McManus, et al., 2018) and correctional settings (American Academy of Pediatrics, 2011). Access to quality care may help adolescents avoid health problems, help them recover more quickly, and/or help to monitor chronic conditions in order to reduce the risk of stress proliferation (Kort-Butler, 2017). Similarly, access to age-appropriate health care that is attuned to psychological and behavioral needs may help adolescents connect to intervention programs (Reijneveld et al., 2014). For instance, programs that assist adolescents in building a physically healthy lifestyle may benefit the way that young people feel about themselves, encourage valuation of conventional goals, and promote prosocial behavior (Semenza, 2018). Adequate, comprehensive care in juvenile residential facilities - where so many adolescents experience comorbidity, a history of accumulated stressors, and current stressful circumstances associated with offending and confinement - may also stem stress proliferation and concomitant harms. 


\section{References}

Adkins, D. E., Wang, V., Dupre, M. E., Van den Oord, E. J., \& Elder Jr, G. H. (2009). Structure and stress: Trajectories of depressive symptoms across adolescence and young adulthood. Social Forces, 88(1), 31-60.

Agnew, R. (1992). Foundation for a general strain theory of crime and delinquency. Criminology, 30(1), 47-87.

- (2002). Experienced, vicarious, and anticipated strain: An exploratory study on physical victimization and delinquency. Justice Quarterly, 19(4), $603-633$.

- (2006). Pressured into crime: An overview of general strain theory. Los Angeles: Roxbury.

- (2013). When criminal coping is likely: An extension of general strain theory. Deviant Behavior, 34(8), 653-670.

American Academy of Pediatrics. (2011) Policy statement: Health care for youth in the juvenile justice system. Pediatrics, 128(6), 1219-1235.

Amirkhan, J., \& Auyeung, B. (2007). Coping with stress across the lifespan: Absolute vs. relative changes in strategy. Journal of Applied Developmental Psychology, 28(4), 298-317.

Aneshensel, C. S., \& Mitchell, U. A. (2014). The stress process: its origins, evolution, and future. In R. J. Johnson, R. J. Turner, \& B. G. Link (Eds.), Sociology of mental health (pp. 53-74). Cham: Springer.

Arnett, J. J. (1999). Adolescent storm and stress, reconsidered. American Psychologist, 54(5), 317.

Arslan, R. (2016). Psychological maltreatment, emotional and behavioral problems in adolescents: The mediating role of resilience and self-esteem. Child Abuse \& Neglect, 52, 200-209.

Baldwin, S.A., \& Hoffman, J.P. (2002). The dynamics of self-esteem: A growthcurve analysis. Journal of Youth and Adolescence, 31(2), 101-113.

Balistreri, K. S., \& Alvira-Hammond, M. (2016). Adverse childhood experiences, family functioning and adolescent health and emotional well-being. Public Health, 132, 72-78.

Baron, S. W. (2015). Differential social support, differential coercion, and organized criminal activities. Justice Quarterly, 32(6), 1089-1117

- (2018). Strain, criminal propensity, and violence: Examining the role of the composite moderator in Agnew's extension to GST. Crime \& Delinquency, doi.org/10.1177/0011128718787511.

Botchkovar, E., \& Broidy, L. (2013). Accumulated strain, negative emotions, and crime: A test of general strain theory in Russia. Crime and Delinquency, 59(6), 837-860.

Bouffard, L. A., \& Koeppel, M. D. (2014). Understanding the potential longterm physical and mental health consequences of early experiences of victimization. Justice Quarterly, 31(3), 568-587. 
Brezina, T., \& Azimi, A. M. (2018). Social support, loyalty to delinquent peers, and offending: an elaboration and test of the differential social support hypothesis. Deviant Behavior, 39(5), 648-663.

Brown, J. S., Meadows, S. O., \& Elder Jr, G. H. (2007). Race-ethnic inequality and psychological distress: Depressive symptoms from adolescence to young adulthood. Developmental Psychology, 43(6), 1295.

Burger, K., \& Samuel, R. (2017). The role of perceived stress and self-efficacy in young people's life satisfaction: A longitudinal study. Journal of Youth and Adolescence, 46(1), 78-90.

Carr, D., \& Umberson, D. (2013). The social psychology of stress, health, and coping. In J. DeLamater J. \& A. Ward (Eds.), Handbook of social psychology, $2^{\text {nd }}$ ed. (pp. 465-487). Dordrecht: Springer.

Capowich, G. E., Mazerolle, P., \& Piquero, A. (2001). General strain theory, situational anger, and social networks: An assessment of conditioning influences. Journal of Criminal Justice, 29(5), 445-461.

Casey, B. J., Jones, R. M., \& Somerville, L. H. (2011). Braking and accelerating of the adolescent brain. Journal of Research on Adolescence, 21(1), 21-33.

Chu, P. S., Saucier, D. A., \& Hafner, E. (2010). Meta-analysis of the relationships between social support and well-being in children and adolescents. Journal of Social and Clinical Psychology, 29(6), 624-645.

Clarke, A. T. (2006). Coping with interpersonal stress and psychosocial health among children and adolescents: A meta-analysis. Journal of Youth and Adolescence, 35(1), 10-23.

Colvin, M., Cullen, F. T., \& Ven, T. V. (2002). Coercion, social support, and crime: An emerging theoretical consensus. Criminology, 4O(1), 19-42.

Compas, B. E., Jaser, S. S., Dunn, M. J., \& Rodriguez, E. M. (2012). Coping with chronic illness in childhood and adolescence. Annual Review of Clinical Psychology, 8, 455-480.

Cornwell, B. (2003). The dynamic properties of social support: Decay, growth, and staticity, and their effects on adolescent depression. Social Forces, 81(3), 953-978.

Craig, J. M., Cardwell, S. M., \& Piquero, A. R. (2017). The effects of criminal propensity and strain on later offending. Crime \& Delinquency, 63(13), 1655-1681.

Cullen, F. T. (1994). Social support as an organizing concept for criminology. Justice Quarterly, 11(4), 527-559.

Cullen, F. T., Wright, J. P., \& Chamlin, M. B. (1999). Social support and social reform: A progressive crime control agenda. Crime and Delinquency, 45(2), 188-207.

DeCoster, S., \& Kort-Butler, L. A. (2006). How general is general strain theory? Assessing determinacy and indeterminacy across life domains. Journal of Research in Crime and Delinquency, 43(4), 1-29.

DeCoster, S., \& Thompson, M. S. (2017). Race and general strain theory: Microaggressions as mundane extreme environmental stresses. Justice Quarterly, 34(5), 903-930. 
Dowd, J. B., Palermo, T., Chyu, L., Adam, E., \& McDade, T. W. (2014). Race/ethnic and socioeconomic differences in stress and immune function in The National Longitudinal Study of Adolescent Health. Social Science \& Medicine, 115, 49-55.

DuBois, D. L., Burk-Braxton, C., Swenson, L. P., Tevendale, H. D., Lockerd, E. M., \& Moran, B. L. (2002). Getting by with a little help from self and others: Self-esteem and social support as resources during early adolescence. Developmental Psychology, 38(5), 822.

Dupéré, V., Leventhal, T., \& Vitaro, F. (2012). Neighborhood processes, selfefficacy, and adolescent mental health. Journal of Health and Social Behavior, 53(2), 183-198.

Eisman, A. B., Lee, D. B., Hsieh, H. F., Stoddard, S. A., \& Zimmerman, M. A. (2018). More than just keeping busy: The protective effects of organized activity participation on violence and substance use among urban youth. Journal of Youth and Adolescence, doi.org/10.1007/s10964-018-0868-8.

Fergus, S., \& Zimmerman, M. A. (2005). Adolescent resilience: A framework for understanding healthy development in the face of risk. Annual Review of Public Health, 26, 399-419.

Ferro, M. A., \& Boyle, M. H. (2015). The impact of chronic physical illness, maternal depressive symptoms, family functioning, and self-esteem on symptoms of anxiety and depression in children. Journal of Abnormal Child Psychology, 43(1), 177-187.

Foster, H., \& Brooks-Gunn, J. (2009). Toward a stress process model of children's exposure to physical family and community violence. Clinical Child and Family Psychology Review, 12(2), 71-94.

Ford, J. A. (2014). Poor health, strain, and substance use. Deviant Behavior, 35(8), 654-667.

Froggio, G. \& Agnew, R. (2007). The relationship between crime and "objective" versus "subjective" strains. Journal of Criminal Justice, 35(1), 81-87.

Goodman, E., McEwen, B. S., Dolan, L. M., Schafer-Kalkhoff, T., \& Adler, N. E. (2005). Social disadvantage and adolescent stress. Journal of Adolescent Health, 37(6), 484-492.

Gore, S., \& Colten, M. E. (1991). Introduction: Adolescent stress, social relationships, and mental health. In M. E. Colten \& S. Gore (Eds.), Adolescent stress: Causes and consequences (pp. 1-14). New York: Aldine de Gruyter.

Grant, K. E., McMahon, S. D., Duffy, S. N., Taylor, J. J., \& Compas, B. E. (2010). Stressors and mental health problems in childhood and adolescence. In R. Contrada \& A. Baum (Eds.), Handbook of stress science: Biology, psychology, and health. (pp. 359-372). New York: Springer.

Greene, M .L, \& Way, N. (2005). Self-esteem trajectories among ethnic minority adolescents: A growth curve analysis of the patterns and predictors of change. Journal of Research on Adolescence, 15(2), 151-178.

Hagan, J., \& Foster, H. (2003). S/He's a rebel: Toward a sequential stress theory of delinquency and gendered pathways to disadvantage in emerging adulthood. Social Forces, 82(1), 53-86. 
Hall, J. E., Simon, T. R., Mercy, J. A., Loeber, R., Farrington, D. P., \& Lee, R. D. (2012). Centers for Disease Control and Prevention's expert panel on protective factors for youth violence perpetration: Background and overview. American Journal of Preventive Medicine, 43(2), S1-S7.

Hoffmann, J. P., \& Cerbone, F. G. (1999). Stressful life events and delinquency escalation in early adolescence. Criminology, 37(2), 343-374.

Jackson, D. B., \& Vaughn, M. G. (2018). Promoting health equity to prevent crime. Preventive Medicine, 113, 91-94.

Jang, S. J., \& Johnson, B. R. (2003). Strain, negative emotions, and deviant coping among African Americans: A test of general strain theory. Journal of Quantitative Criminology, 19(1), 80-105.

Juster, R. P., McEwen, B. S., \& Lupien, S. J. (2010). Allostatic load biomarkers of chronic stress and impact on health and cognition. Neuroscience \& Biobehavioral Reviews, 35(1), 2-16.

Johnson, M. K., Crosnoe, R., \& Elder, G. H. (2011). Insights on adolescence from a life course perspective. Journal of Research on Adolescence, 21(1), 273-280.

Junger, M., Stroebe, W., \& Van der Laan, A. (2001). Delinquency, health behavior, and health. British Journal of Health Psychology, 6(2), 103-120.

Keane, L., \& Loades, M. (2017). Low self-esteem and internalizing disorders in young people-a systematic review. Child and Adolescent Mental Health, 22(1), 4-15.

Knight, K. E., Ellis, C., Roark, J., Henry, K. L., \& Huizinga, D. (2017). Testing the role of aspirations, future expectations, and strain on the development of problem behaviors across young and middle adulthood. Deviant Behavior, 38(12), 1456-1473.

Kort-Butler, L. A. (2009). Coping styles and sex differences in depressive symptoms and delinquent behavior. Journal of Youth and Adolescence, 38(1), 122-136.

-.(2010). Experienced and vicarious victimization: Do social support and self-esteem prevent delinquent responses? Journal of Criminal Justice, 38(4), 496-505.

-.(2017). Health-related strains and subsequent delinquency and marijuana use. Youth \& Society, 49(8), 1077-1103.

Krok, D. (2015). Religiousness, spirituality, and coping with stress among late adolescents: A meaning-making perspective. Journal of Adolescence, 45, 196-203.

Low, N. C., Dugas, E., O’Loughlin, E., Rodriguez, D., Contreras, G., Chaiton, M., \& O'Loughlin, J. (2012). Common stressful life events and difficulties are associated with mental health symptoms and substance use in young adolescents. BMC Psychiatry, 12(1), https://doi.org/10.1186/1471-244X-12-116

Lee, E. J., \& Stone, S. I. (2012). Co-occurring internalizing and externalizing behavioral problems: the mediating effect of negative self-concept. Journal of Youth and Adolescence, 41(6), 717-731.

Lewis, D. M. (2017). A matter for concern: young offenders and the importance of mattering. Deviant Behavior, 38(11), 1318-1331. 
Lucas-Thompson, R. G., Lunkenheimer, E. S., \& Dumitrache, A. (2017). Associations between marital conflict and adolescent conflict appraisals, stress physiology, and mental health. Journal of Clinical Child \& Adolescent Psychology, 46(3), 379-393.

McEwen, B. S., \& Gianaros, P. J. (2010). Central role of the brain in stress and adaptation: links to socioeconomic status, health, and disease. Annals of the New York Academy of Sciences, 1186(1), 190-222.

McLeod, J. D. (2012). The meanings of stress: Expanding the stress process model. Society and Mental Health, 2(3), 172-186.

McLeod, J. D., Uemura, R., \& Rohrman, S. (2012). Adolescent mental health, behavior problems, and academic achievement. Journal of Health and Social

Behavior, 53(4), 482-497.

Meadows, S. O., Brown, J. S., \& Elder, G. H. (2006). Depressive symptoms, stress, and support: Gendered trajectories from adolescence to young adulthood. Journal of Youth and Adolescence, 35(1), 89-99.

Mier, C., \& Ladny, R. T. (2018). Does Self-esteem Negatively Impact Crime and Delinquency? A Meta-analytic Review of 25 Years of Evidence. Deviant Behavior, 39(8), 1006-1022.

Mirowsky, J., \& Ross, C. E. (2003). Social causes of psychological distress, $2^{\text {nd }}$ ed. New York: Routledge.

Moon, B., \& Morash, M. (2017). A test of general strain theory in South Korea: A focus on objective/subjective strains, negative emotions, and composite conditioning factors. Crime \& Delinquency, 63(6), 731-756.

Moon, B., Morash, M., McClusky, C. P., \& Hwang, H. (2009). A comprehensive test of general strain theory: Key strains, situational- and trait-based negative emotions, conditioning factors, and delinquency. Journal of Research in Crime and Delinquency, 46, 182-212.

National Research Council. (2002). Community programs to promote youth development. Washington, D.C.: National Academies Press.

Ott, M. A., Rosenberger, J. G., McBride, K. R., \& Woodcox, S. G. (2011). How do adolescents view health? Implications for state health policy. Journal of Adolescent Health, 48(4), 398-403.

Panuccio, E. A., Christian, J., Martinez, D. J., \& Sullivan, M. L. (2012). Social support, motivation, and the process of juvenile reentry: An exploratory analysis of desistance. Journal of Offender Rehabilitation, 51(3), 135-16o.

Pearlin, L. I. (1989). The sociological study of stress. Journal of Health and Social Behavior, 30(3), 241-256.

Pearlin, L. I. (1999). The stress concept revisited. In C. S. Aneshensel \& J. C. Phelan (Eds.), Handbook of the sociology of mental health (pp. 395-415). New York: Kluwer Academic/PlenumPublishers.

Pearlin, L. I., \& Bierman, A. (2013). Current issues and future directions in research into the stress process. In C. S. Aneshensel, J. C. Phelan, \& A. Bierman (Eds.), Handbook of the sociology of mental health (pp. 325-340). Dordrecht: Springer. 
Pearlin, L. I., Schieman, S., Fazio, E. M., \& Meersman, S. C. (2005). Stress, health, and the life course: Some conceptual perspectives. Journal of Health and Social Behavior, 46(2), 205-219.

Pinquart, M., \& Shen, Y. (2011). Behavior problems in children and adolescents with chronic physical illness: A meta-analysis. Journal of Pediatric Psychology, 36(9), 1003-1016.

Piquero, A.R., Daigle, L.E., Gibson, C., Piquero, N.L., \& Tibbetts, S.G. (2007). Are life-course-persistent offenders at risk for adverse health outcomes? Journal of Research in Crime \& Delinquency, 44(2), 185-207.

Reijneveld, S. A., Wiegersma, P. A., Ormel, J., Verhulst, F. C., Vollebergh, W. A., \& Jansen, D. E. (2014). Adolescents' use of care for behavioral and emotional problems: types, trends, and determinants. PLoS One, 9(4), e93526, https:// doi.org/10.1371/journal.pone.0093526

Rose, T., Sharpe, T. L., Shdaimah, C., \& deTablan, D. (2017). Exploring coping among urban youth through photovoice. Qualitative Social Work, https://doi. org/10.1177/1473325017693684

Rosenberg, M. (1989). Society and the adolescent self-image, revised edition. Middletown, CT: Wesleyan University Press

Rueger, S. Y., Malecki, C. K., Pyun, Y., Aycock, C., \& Coyle, S. (2016). A metaanalytic review of the association between perceived social support and depression in childhood and adolescence. Psychological Bulletin, 142 (10), 107-1067.

Saewyc, E. M. (2011). Research on adolescent sexual orientation: Development, health disparities, stigma, and resilience. Journal of Research on Adolescence, 21(1), 256-272.

Schönfeld, P., Brailovskaia, J., Bieda, A., Zhang, X. C., \& Margraf, J. (2016). The effects of daily stress on positive and negative mental health: Mediation through self-efficacy. International Journal of Clinical and Health Psychology, 16(1), 1-10.

Sealock, M. D., \& Manasse, M. (2012). An uneven playing field: The impact of strain and coping skills on treatment outcomes for juvenile offenders. Journal of Criminal Justice, 40(3), 238-248.

Seiffge-Krenke, I. (2000). Causal links between stressful events, coping style, and adolescent symptomatology. Journal of Adolescence, 23(6), 675-691.

Seiffge-Krenke, I., Aunola, K., \& Nurmi, J. E. (2009). Changes in stress perception and coping during adolescence: The role of situational and personal factors. Child Development, 80(1), 259-279.

Semenza, D. C. (2018). Health behaviors and juvenile delinquency. Crime \& Delinquency, 64, 1394-1416.

Sharp, S. F., Brewster, D., \& Love, S. R. (2005). Disentangling strain, personal attributes, affective response and deviance: A gendered analysis. Deviant Behavior, 26(2), 133-157.

Sigfusdottir, I. D., Kristjansson, A. L., \& Agnew, R. (2012). A comparative analysis of general strain theory. Journal of Criminal Justice, 40, 117-127. 
Sigfusdottir, I. D., Kristjansson, A. L., Thorlindsson, T., \& Allegrante, J. P. (2016). Stress and adolescent well-being: the need for an interdisciplinary framework. Health Promotion International, 32(6), 1081-1090.

Slocum, L. E. (2010). General strain theory and the development of stressors and substance use over time: An empirical examination. Journal of Criminal Justice, 38(6), 1100-1112.

Spencer, D. L., McManus, M., Call, K. T., Turner, J., Harwood, C., White, P., \& Alarcon, G. (2018). Health care coverage and access among children, adolescents, and young adults, 2010-2016: Implications for future health reforms. Journal of Adolescent Health, 62(6), 667-673.

Spencer, R., Walsh, J., Liang, B., Mousseau, A. M. D., \& Lund, T. J. (2018). Having it all? A qualitative examination of affluent adolescent girls' perceptions of stress and their quests for success. Journal of Adolescent Research, 33(1), 3-33.

Stogner, J. M. (2015). DAT1 and alcohol use: differential responses to life stress during adolescence. Criminal Justice Studies, 28(1), 18-38.

Stogner, J., \& Gibson, C. L. (2010). Healthy, wealthy, and wise: Incorporating health issues as a source of strain in Agnew's general strain theory. Journal of Criminal Justice, 38(6), 1150-1159.

Surís, J. C., Michaud, P. A., Akre, C., \& Sawyer, S. M. (2008). Health risk behaviors in adolescents with chronic conditions. Pediatrics, 122(5), e1113-e1118. DOI: 10.1542/peds.2008-1479

Thoits, P. A. (1995). Stress, coping, and social support processes: Where are we? What next? Journal of Health and Social Behavior, Extra Issue, 53-79.

- (2010). Stress and health: Major findings and policy implications. Journal of Health and Social Behavior, 51, S41-S53.

- (2011). Mechanisms linking social ties and support to physical and mental health." Journal of Health and Social Behavior, 52, 145-161.

Turner, R. J. (2010). Understanding health disparities: The promise of the stress process model. In W. R. Avison, C. S. Aneshensel, S. Schieman, \& B. Wheaton (Eds.), Advances in the conceptualization of the stress process (pp. 3-21). New York: Springer

Turner, R. J., \& Lloyd, D. A. (1999). The stress process and the social distribution of depression. Journal of Health and Social Behavior, 40, 374-404.

Trzesniewski, K. H., Donnellan, M. B., Moffitt, T. E., Robins, R. W., Poulton, R., \& Caspi, A. (2006). Low self-esteem during adolescence predicts poor health, criminal behavior, and limited economic prospects during adulthood. Developmental Psychology, 42(2), 381.

Tyler, K. A., Kort-Butler, L., \& Swendener, A. (2014). The effect of victimization, mental health, and protective factors on crime and illicit drug use among homeless young adults. Violence \& Victims, 29(2), 348-362.

Tyler, K. A., Olson, K., \& Ray, C. M. (2018). Understanding the Link between Victimization and Alcohol Use among Homeless Youth Using Ecological Momentary Assessment. Socius, 4, https://doi.org/10.1177/2378023118779832 
Voisin, D. R., Kim, D. H., Bassett, S. M., \& Marotta, P. L. (2018). Pathways linking family stress to youth delinquency and substance use: exploring the mediating roles of self-efficacy and future orientation. Journal of Health Psychology, https://doi.org/10.1177/1359105318763992

Wade, R., Shea, J. A., Rubin, D., \& Wood, J. (2014). Adverse childhood experiences of low-income urban youth. Pediatrics, 134(1), e13-e20, http://pediatrics. aappublications.org/content/134/1/e13

Wade, T. J., \& Pevalin, D. J. (2005). Adolescent delinquency and health. Canadian Journal of Criminology and Criminal Justice, 47(4), 619-654.

Warner, T. D., \& Settersten, R. A. (2017). Why neighborhoods (and how we study them) matter for adolescent development. Advances in Child Development and Behavior, 52, 105-152.

Wheaton, B. (2010). The stress process as a successful paradigm. In W. R. Avison, C. S. Aneshensel, S. Schieman, \& B. Wheaton (Eds.), Advances in the conceptualization of the stress process (pp. 231-252). New York: Springer.

Wheaton, B., Young, M., Montazer, S., \& Stuart-Lahman, K. (2013). Social stress in the twenty-first century. In C. S. Aneshensel, J. C. Phelan, \& A. Bierman (Eds.), Handbook of the sociology of mental health (pp. 299-323). Dordrecht: Springer.

Wickrama, K. A., Lee, T. K., \& O’Neal, C. W. (2015). Stressful life experiences in adolescence and cardiometabolic risk factors in young adulthood. Journal of Adolescent Health, 56(4), 456-463.

Wight, R. G., Botticello, A. L., \& Aneshensel, C. S. (2006). Socioeconomic context, social support, and adolescent mental health: A multilevel investigation. Journal of Youth and Adolescence, 35, 109-120.

Yeager, D. S., Lee, H. Y., \& Jamieson, J. P. (2016). How to improve adolescent stress responses: Insights from integrating implicit theories of personality and biopsychosocial models. Psychological Science, 27(8), 1078-1091.

Yeung, R., \& Leadbeater, B. (2010). Adults make a difference: the protective effects of parent and teacher emotional support on emotional and behavioral problems of peer-victimized adolescents. Journal of Community Psychology, 38(1), 80-98.

Zimmer-Gembeck, M. J., \& Skinner, E. A. (2011). The development of coping across childhood and adolescence: An integrative review and critique of research. International Journal of Behavioral Development, 35(1), 1-17. 